\title{
Assessment of outcome of an ADHD treatment program using parent feedback
}

\author{
Hemamali Perera, Kamal Chandima Jeewandara, Sudharshi Seneviratne and Chandima Guruge
}

\section{Background}

Attention deficit hyperactivity disorder (ADHD) is a common behaviour disorder in children where the associated aggressive tendencies, learning difficulties and poor social skills pose a substantial burden of care on the parents. However, in traditional clinical practice, parental expectation of outcome of treatment is rarely considered.

\section{Aims}

This study prospectively analysed an outpatient treatment programme for children with ADHD, where parents provided feedback on the outcome of treatment.

\section{Methods}

Parents completed structured formats to provide information on presenting complaints, outcome at 3 months and 6 months after commencing treatment and side effects of the drug methylphenidate. Parents also attended psycho-educational and support groups.

\section{Results}

Of the 102 patients, parents reported a positive outcome in the majority. There was significantly better improvement in symptoms of ADHD at 6 months when compared to 3 months of treatment $(p<0.005)$. Also, hyperactivity improved more than attention deficit and impulsiveness at the end of 6 months, though persistence of learning difficulties (50\%) and disruptive behaviour were causes for dissatisfaction about treatment. The commonest side effect was poor appetite (49\%), though none of the children had identifiable weight loss.

\section{Conclusions}

Close involvement of parents in monitoring outcome of treatment of ADHD helps to focus on aspects of care relevant to them.

SL J Psychiatry 2010; 1 (2):51-55

\section{Introduction}

This paper reports the outcome of a routine outpatient treatment programme for children with attention deficit hyperactivity disorder (ADHD) conducted by a specialist child mental health service. Here, the parents played an essential role in evaluating the outcome of treatment / intervention. The purpose of involving parents was mainly threefold. Firstly, multi modal treatment, where parent participation in behavioural management is an important component, is favoured due to its strong evidence base for effectiveness, as opposed to drug treatment alone $(1,2)$. Accordingly, selected non-pharmacological interventions are used to improve learning, prevent school failure, promote emotional adjustment and self esteem in the child, and relieve the distress in the family $(3,4)$. Secondly, in traditional clinical practice, the outcome of treatment is usually measured using medical criteria and the experience of the clinician. Expectation of the parents regarding the outcome of treatment is often given much less importance, although ADHD causes substantial burden on parents. Their burden is compounded by poor knowledge about the disorder and perceived lack of control over the child's behaviour $(5,6)$. Also, the importance of family and parent factors related to compliance of stimulant medication in ADHD is well recognised (7). Poor compliance is a risk if parents are unable to understand or are dissatisfied about medical management, as they are guided by their own sociocultural beliefs about the cause of behaviour problems in ADHD and the use of medical treatment (8). Thirdly, scarcity of resources in child mental health care in Sri Lanka requires parents to be self-advocates in improving the quality of life of children with ADHD. Such systems of care for children with ADHD and their benefits have been reported from some developing countries (9).

\section{Objective}

The main objective was to study the outcome of the outpatient ADHD treatment programme from the perspective of the parents, using structured feedback reports. The specific objectives were to evaluate the outcome at 3 months and 6 months after commencement of treatment, adverse effect of medication and symptoms of ADHD that did not respond or partially responded to treatment / intervention.

\section{Methods}

Clinical diagnosis of ADHD was made using DSM IV criteria (10). Prospective patient data was systematically gathered and documented on entry to the programme and on follow up. Intervention was uniform as all children were given the benefit of all components of the programme. Different components of the programme were as follows.

1. Immediate-release methylphenidate (MPH), 


\begin{tabular}{|lc|}
\hline \multicolumn{2}{|l|}{ Table $1-$ Frequency distribution of age groups } \\
\hline Age group & Frequency $(\%)$ \\
\hline 4 years & $8(7.8 \%)$ \\
$5-9$ years & $78(77.5 \%)$ \\
$\geq 10$ years & $15(14.7 \%)$ \\
Total & $102(100 \%)$ \\
\hline
\end{tabular}

which was prescribed on the basis of the age, body weight, and the severity of symptoms. All children were reviewed, initially fortnightly, and later monthly. Their body weights were recorded at each visit.

2. Educational intervention for children was provided by education and occupational therapists irrespective of the presence or absence of significant reading / spelling disability, as all children had cognitive problems affecting their educational functioning.

3. Initial psychoeducation of parents on ADHD was further strengthened with a leaflet, which also included information on simple behavioural strategies for practice at home.

4. Similar printed information for teachers on classroom management of ADHD was given to parents to be handed over to teachers.

5. Group meetings for parents were conducted by medical staff to provide psycho-education, support and guidance.

The parents provided information and feedback on following structured formats:

i. A 10 item check list of symptoms of ADHD and associated behavioural and learning difficulties. Parents responded by indicating "present" or "absent" against each item on the list at the time of entering the treatment programme.

ii. The parents reported an overall outcome at 3 months and 6 months after commencing treatment as "improved" or "not improved".

iii. A 7 item checklist of known side effects of MPH. Parents responded by indicating "present" or "absent", which was recorded on a weekly basis, in the first four weeks.

Data used for this article is confined to those children who consistently attended clinics and completed six months of treatment / intervention. Children with

Table 2 - Frequency distribution of the presenting complaints reported by parents

\begin{tabular}{|lc|}
\hline Presenting complaint & Frequency(\%) \\
\hline Hyperactivity & $92(88.5)$ \\
Attention deficit & $83(79.8)$ \\
Impulsiveness & $63(59.6)$ \\
Uncooperative behaviour & $47(45.2)$ \\
Antisocial behaviour & $36(34.6)$ \\
Learning difficulties & $25(24.0)$ \\
Peer relationship problems & $58(55.8)$ \\
Disruptive behaviour & $34(32.7)$ \\
Aggressive behaviour & $29(27.9)$ \\
Other & $8(7.7)$ \\
\hline
\end{tabular}

\begin{tabular}{|c|c|}
\hline Side effect & Frequency $(\%)$ \\
\hline No side effects & 27 (25.9) \\
\hline Loss of appetite & $51(49.0)$ \\
\hline Social withdrawal & $6(5.8)$ \\
\hline Restlessness & $5(4.8)$ \\
\hline Abdominal pain & $15(14.4)$ \\
\hline Headache & $13(12.5)$ \\
\hline Poor sleep & $13(12.5)$ \\
\hline Sadness & $13(12.5)$ \\
\hline
\end{tabular}

Table 4 - Overall outcome of interventions at 3 months
and 6 months based on parental ratings
\begin{tabular}{lcc|}
\hline Parent rating of & 3 months & 6 months \\
outcome & Frequency $(\%)$ & Frequency (\%) \\
\hline Improved & $78(76.47)$ & $84(82.35)$ \\
Not improved & $24(23.53)$ & $18(17.65)$ \\
Total & $102(100)$ & $102(100)$ \\
\hline
\end{tabular}

$\mathrm{x} 2=56.3, \mathrm{df}=2, \mathrm{p}<0.005$

ADHD found to be unsuitable for treatment with MPH being less than 4 years of age, or for any other reason, were excluded.

\section{Results}

Data on 102 children was available for analysis. The age distribution of the sample was 4 to 12 years with a mean age of 6.92 years (SD 2.045). Table 1 gives the frequency distribution of age groups.

Ninety children $(88.23 \%)$ were male. The doses of MPH used in the treatment ranged from $2.5 \mathrm{mg}$ to $40 \mathrm{mg}$ per day. There were 19 (18.3\%) children who were also taking other medications on a regular basis. These were anticonvulsants in $15(14.4 \%)$ and anti asthmatic drugs in the rest $4(3.9 \%)$.

\section{Main presenting problems identified by the parents}

Response of parents to the 10 item checklist of symptoms is shown in Table 2.

\section{Side effects of medication}

Table 3 gives the frequency distribution of side effects reported by the parents. The commonest side effects reported were poor appetite, headache and abdominal pain. Cross tabulation did not show a significant association between the dose of MPH and these symptoms $(\mathrm{p}>0.05)$. All the $50(49 \%)$ children who were reported to have loss of appetite remained stable in their body weights throughout the period of study. The parents did not report any other side effect beyond the initial 4 weeks except poor appetite. None of the 
Table 5 - Frequency of persisting symptoms reported by parents following 6 months of treatment

\begin{tabular}{|ll|}
\hline Persisting symptoms & Frequency(\%) \\
\hline Hyperactivity & $27(26.0)$ \\
Attention deficit & $32(30.8)$ \\
Impulsiveness & $12(11.5)$ \\
Disruptive behaviour & $38(36.5)$ \\
Emotional problems & $14(13.5)$ \\
Learning difficulties & $52(50.0)$ \\
Peer relationship problems & $11(10.6)$ \\
\hline
\end{tabular}

children required discontinuation of medication due to side effects.

\section{Outcome of treatment based on parents' assessment}

Table 4 gives the overall outcome of management at 3 months and 6 months based on the assessment of parents whether the child has "improved" or "not improved". It takes into account that at baseline, all the children were positive for the cardinal symptoms of ADHD. The proportion of children rated by parents as "improved" at 6 months was higher compared to that at 3 months, and this difference was statistically significant $(p<0.005)$. With regard to individual symptoms, the reported difference was greater for hyperactivity than for attention and impulsiveness, as shown in Figure 1. There was no statistically significant relationship between the age of the child and the outcome of treatment at 3 months or 6 months $(p>0.05)$.
Parents also identified certain persistent symptoms (Table 5), where the outcome of treatment was unsatisfactory in their opinion. Most commonly identified problems were learning difficulties and disruptive behaviour. There was no statistically significant relationship between the age of the child and dissatisfaction in parents about persistent behaviour problems $(p>0.05)$. The relationship between the age of child and parent identified learning difficulties was significant at $\mathrm{p}<0.05$.

\section{Discussion}

Parents reported an overall positive outcome in the majority of children. Also, improvement of symptoms continued to progress as treatment continued indicating that a longer period of treatment was beneficial. This was shown as a positive outcome, which was statistically significant from 3 months to 6 months. The parents reported greater improvement in hyperactivity than attention deficit and impulsiveness at the end of 6 months of treatment. The parents were dissatisfied that the difficulties in learning and disruptive behaviours were not reduced to the extent they anticipated. Also, the persistence of learning difficulties $(50.0 \%)$ and disruptive behaviour $(36.8 \%)$ was identified by parents (Table 5), indicating some degree of dissatisfaction with the programme. This was despite a statistically significant overall improvement $(\mathrm{p}<0.005)$ at 6 months compared to that at 3 months. Other studies support these findings where $42 \%$ of antisocial and disruptive behaviour was shown to persist despite treatment in ADHD $(11,12)$. Also, over $39 \%$ of children with ADHD are said to need continued support from mental health and education services (13). Information provided

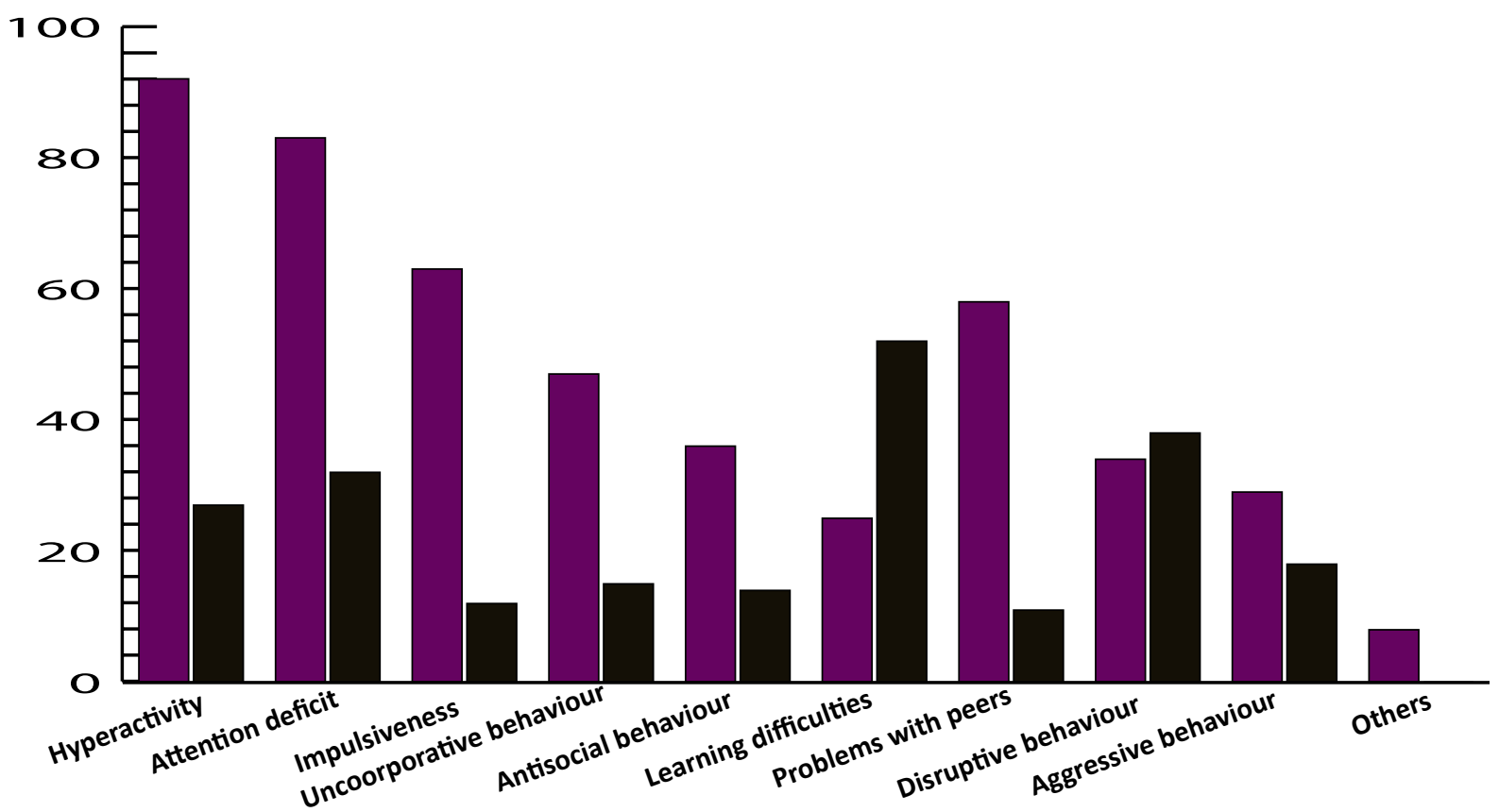

Fig. 1 Frequency of individual symptoms at entry into programme and at 6 months following treatment 
by parents is known to correlate well with structured rating for ADHD and related behaviour disorders (14). Hence, the reliability of parents' reports as sources of clinical information is established to some extent.

There were two areas where discrepancy between the parent and clinician perception of ADHD and its management was apparent. The first was regarding the clinical diagnosis of ADHD which is based on the presence of hyperactivity, inattentiveness and impulsivity in all cases (10). Clinically, treatment aims at remission of these features. All three cardinal features were identified in the majority of children by their parents (Table 2). However, it is also relevant to note that hyperactivity, inattentiveness and impulsivity was not reported in $11.5 \%, 20.2 \%$ and $40.4 \%$ of children respectively. This finding indicates that some parents may not have considered these features as symptoms or disabilities. In contrast, parents who did not identify learning difficulties on entry to the programme, identified its presence at the end of 6 months of treatment (Table 5). The second area of discrepancy was regarding the use of stimulant medication and their side effects. Parents and clinicians are known to differ in opinion with regard to MPH use $(8,15,16)$. In our study, loss of appetite was reported in $49 \%$ of cases. However, the monitoring of body weight did not support this finding. Cultural preoccupation with feeding, and direct attention drawn to the problem through the side effect checklist, may have influenced excess reporting. Such discrepancy of opinion may affect treatment adherence and parent satisfaction or even default of medication. Even in the presence of such differences of opinion, the individual components of our treatment programme may have contributed to the overall positive outcome reported by the parents. It is known that adequate information, frequent review, less side effects with medication and parent checklists in assessment individually improve compliance and parent satisfaction $(17,18)$.

Active involvement of parents in measuring outcome and the use of structured formats instead of simple verbal information was a strength of our programme. Active contribution to monitoring the medication has been reported as a beneficial experience to parents $(9,10)$. Also, support groups for parents are known to improve disciplinary patterns, efficacy of parenting, and compliance with treatment of ADHD, resulting in better outcome $(16,19,20)$. Significant reduction in socially undesirable behaviour in children with ADHD has been reported after parent training $(21,22,23)$. Although the treatment package offered included pharmacological, behavioural and educational interventions, it was not possible to evaluate their individual effects. Though the parents actively participated in evaluating outcome of treatment, their attitude to a partnership with doctors that was unfamiliar to them was also not assessed by us. Lack of data on children who dropped out is a shortcoming, as it prevented the understanding of possible reasons for non-adherence with treatment. Considering the concern shown by mothers about appetite problems related to MPH, perhaps this was one reason for dropout. Teachers not being involved in evaluating outcome is another drawback.

\section{Clinical relevance}

This study helps in developing a model for outpatient management of children with ADHD, in collaborative partnership with parents. This close involvement of parent in the management allows the opportunity to focus on aspects of care that is relevant to the child and family rather than symptom reduction alone. Also, as parent satisfaction and benefit to the child improved with time and continuation of treatment, all attempts should be made to encourage compliance.

\section{Declaration of interest}

None

Hemamali Perera,MBBS,MD(Psych),FRCPsych Professor, Department of Psychological Medicine, Faculty of Medicine, University of Colombo, Sri Lanka

Kamal Chandima Jeewandara, MBBS, Medical Officer in Psychiatry, Lady Ridgeway Hospital, Colombo, Sri Lanka Sudharshi Seneviratne, MBBS,MD(Psych), Lecturer, Department of Psychological Medicine, Faculty of Medicine, University of Colombo, Sri Lanka

Chandima Guruge, MBBS, Medical Officer in Psychiatry, Lady Ridgeway Hospital, Colombo, Sri Lanka Corresponding author

Hemamali Perera, Department of Psychological

Medicine, Faculty of Medicine, Colombo 08, Sri Lanka

E mail: hemamali_p@yahoo.com

\section{References}

1. American Academy of Pediatrics. Subcommittee on Attention-Deficit/Hyperactivity Disorder and Committee on Quality Improvement. Clinical practice guideline: treatment of the school-aged child with attention-deficit/hyperactivity disorder. Pediatrics 2001; 108: 1033-1044.

2. Pliszka S. American Academy of Child and Adolescent Psychiatry Work Group on Quality Issues. Practice parameter for the assessment and treatment of children and adolescents with attention-deficit/hyperactivity disorder. J Am Acad Child Adolesc Psychiatry 2007; 46: 894-921.

3. Overmeyer S, Taylor E. Annotation: Principles of treatment for hyperkinetic disorder: practice approaches for the U.K. J Child Psychol Psychiatry 1999; 40: 1147-1157.

4. DuPaul GJ, McGoey KE, Eckert TL, VanBrakle J. Preschool children with attention-deficit/hyperactivity disorder: impairments in behavioral, social, and school functioning. J Am Acad Child Adolesc Psychiatry 2001; 40: 508-515.

5. Harrison C, Sofronoff K. ADHD and parental psychological distress: role of demographics, child behavioral characteristics, and parental cognitions. J Am Acad Child Adolesc Psychiatry 2002; 41: 703-711.

6. Bailey RK, Owens DL. Overcoming challenges in the diagnosis and treatment of attention-deficit/ hyperactivity disorder in African Americans. J Natl Med Assoc 2005; 97(10 suppl): 5S-10S 
7. Gau SSF, Hsin-Yi Shen, Miao-Churn Chou, Chin-Shu tang, Yen-Nan Chiu, Churn-Shiouh Gan. Determinants of adherence to MPH and the impact of poor adherence on maternal and family measures. J Child Adolesc Psychopharmacol 2006; 16: 286

8. Dosreis S, Zito JM, Safer DJ, Soeken KL, Mitchell JW Jr, Ellwood LC. Parental perceptions and satisfaction with stimulant medication for attention-deficit hyperactivity disorder. J Dev Behav Pediatr 2003; 24 : 155-162.

9. Fayyad JA, Jahshan CS, Karam EG. Systems development of child mental health services in developing countries. Child Adolesc Psychiatr Clin N Am 2001; 10: 745-762

10. Diagnostic and Statistical Manual of Mental Disorders, Fourth Edition. American Psychiatric Association, Washington DC 1994.

11. Huang HL, Chao CC, Tu CC, Yang PC. Behavioural parent training for Taiwanese of children with attention-deficit / hyperactivity disorder. Psychiatry Clin Neurosci 2003; 57: 275-281

12. Biederman J, Mick E, Farone S, Burback M. Patterns of remission and symptom decline in conduct disorder: a four year prospective study of an ADHD sample. J Am Acad Child Adolesc Psychiatry 2001; 40: 290-298

13. Poduska J. Parents' perception of their first graders' need for mental health and educational services. J Am Acad Child Adolesc Psychiatry 2000; 39: 584-591

14. Ickowicz A, Schachar RJ, Sugarman R, Chen SX, Millette C, Cook L. The parent interview for child symptoms: a situation specific research interview for attention-deficit hyperactivity and related disorders. Canadian Journal of Psychiatry 2006; 51: 325-328
15. Vance AL, Maruff P, Barnett R. Attention deficit hyperactivity disorder, combined type: better executive function performance with longer-term psychostimulant medication. Australia and New Zealand Journal Psychiatry 2003; 37: 570-576

16. Hazell PL, Lewin TJ, McDowell MJ, Walton JM. Factors associated with medium-term response to psychostimulant medication. J Paediatr Child Health 1999; 35: 264-268.

17. Schachar RJ, Tannock R, Cunningham C, Corkum PV. Behavioral, situational, and temporal effects of treatment of ADHD with methylphenidate. J Am Acad Child Adolesc Psychiatry 1997; 36: 754-763

18. Efron D, Jarman FC, Barker MJ. Medium-term outcomes are comparable with short-term outcomes in children with attention deficit hyperactivity disorder treated with stimulant medication. J Paediatr Child Health 2000; 36: 457-461

19. Hoza B, Owens JS, Pelham WE, Swanson JM, Conners CK, Hinshaw SP, Arnold LE, Kraemer HC. Parent cognitions as predictors of child treatment response in attention-deficit/hyperactivity disorder. J Abnorm Child Psychol 2000; 28: 569-583

20. Weinberg HA. Parent training for attention-deficit hyperactivity disorder: parental and child outcome. J Clin Psychol 1999; 55: 907-913.

21. Bukstein OG, Kolko DJ. Effects of methylphenidate on aggressive urban children with attention deficit hyperactivity disorder. J Clin Child Psychol 1998; 27: 340-351.

22. Efron D, Jarman FC, Barker MJ. Child and parent perceptions of stimulant medication treatment in attention deficit hyperactivity disorder. J Paediatr Child Health 1998; 34: 288-292.

23. Dubey DR, O'Leary SG, Kaufman KF. Training parents of hyperactive children in child management: a comparative outcome study. J Abnorm Child Psychol 1983; 11: 229-245. 